Monatsschrift f. Geburtshülfe u. Gynäkologie 1933;95:110

\title{
Erkennung und Bekämpfung des Karzinoms
}

\section{Berichtigung zu der Arbeit in Bd. 94 S. 255 dieser Zeitschrift.}

Von

OTTO VON FRANQUÉ in Bonn.

Herr Dr. Schiller-Wien hat mir freundlicherweise mitgeteilt, daß ich auf S. 266 obiger Arbeit die von ihm angegebene Jod-kalireaktion zur leichteren Erkennung von Leukoplakien und krebsverdächtigen Stellen nicht richtig geschildert habe. Er , ,ver-wendet und empfiehlt nicht 2\%ige Jodkalilösung, sondern die weit billigere eindritlelprozenííge, die auch viel distinktere und klarere Eärbungen ergibt. Der Nachteil der dünneren Lösung, daß die Färbung einige Sekunden länger dauert, spielt keine Rolle.”

Ich hielt mich verpflichtet, diese nicht unwesentliche Richtig-stellung zu veröffentlichen. 